prognostic value of 18F-FDG uptake at dysplasia sites was also assessed with surveillance. Can 18F-FDG uptake predict progression of pre-invasive lesions or cancer elsewhere?

Methods 39 patients with pre-invasive endobronchial lesions underwent 18F-FDG PET/CT examination prior to autofluorescence bronchoscopy. Pre-invasive lesions were classified as either highgrade (carcinoma in situ or severe dysplasia) or low grade (mild to moderate dysplasia). The degree of uptake of 18F-FDG was analysed without knowledge of the bronchoscopic or other clinical findings. Results $8 / 39$ patients (all with high grade dysplasia) had increased 18F-FDG uptake at known dysplasia sites. Of these 8 patients 1 had surgical resection of invasive carcinoma and two patients were diagnosed and treated as invasive cancer based on imaging and follow-up. Eight patients had 18F-FDG uptake at sites remote from known dysplasia; $2 / 8$ patients had synchronous invasive lung carcinoma (pT1N0M0), 2/8 recurrent cancer in hilar and mediastinal nodes, and 4/8 patients had inflammatory uptake in lung, mediastinal or hilar nodes. During surveillance of up to 3 years, $3 / 5$ patients with positive 18F-FDG uptake developed biopsy proven invasive cancer at site of dysplasia. $3 / 31$ patients with negative $18 \mathrm{~F}$ FDG uptake developed invasive cancer at high grade dysplasia sites during surveillance. No low grade lesion showed 18F-FDG uptake or progressed to invasive cancer during surveillance.

Conclusions PET/CTwas able to detect early synchronous cancers in patients with pre-invasive endobronchial lesions. PET/CT was also able to detect 18F-FDG uptake in a proportion of patients at known dysplasia sites suggesting adjacent or underlying occult invasive carcinoma.

\section{P162 COMPARISON OF CLINICAL CHARACTERISTICS AND OUTCOMES OF PATIENTS WITH PET POSITIVE VS PET NEGATIVE SOLITARY PULMONARY NODULES MANAGED BY A LUNG MDT}

doi:10.1136/thoraxjnl-2011-201054c.162

P Malhotra, N Lovell, P K Plant, M E J Callister, S Karthik, A Scarsbrook. St James' University Hospital, Leeds, UK

Background PET-CT is an important test in the management of patients with solitary pulmonary nodules (SPNs). There is a paucity of data on clinical characteristics, follow-up and outcomes of patients with PET negative nodules as compared to PET positive ones.

Objective To compare the clinical characteristics and outcomes of patients with PET positive vs PET negative SPNs managed by the Lung MDT at a large teaching hospital in North England.

Methods 144 patients (age range 32-92 years, 76 females) with SPNs measuring 8-29 $\mathrm{mm}$ discussed at the Lung MDT who had PET-CT scans over a 3 year period between 1st January 2007 and 31st December 2009 were identified retrospectively through the Lung Cancer database. Demographic data, nodule characteristics, MDT decisions, median time to diagnosis, and outcomes were evaluated. We tested for differences in characteristics between patients with PET positive and negative nodules using $t$ test and Mann-Whitney $U$ test for continuous variables, and $\chi^{2}$ tests or Fisher exact tests as indicated for categorical variables.

Results In comparison to PET positive nodules, PET negative ones were smaller, less likely to be spiculated, more often associated with an MDT decision to follow-up with serial CT scans, less likely to undergo surgical resection or have radical radiotherapy, had a longer median time to diagnosis, and were less likely to be malignant. The overall prevalence of malignancy in patients with PET negative nodules, however $(15 / 41$ [36.6\%]) was higher than that reported in previous studies. This may be due to the higher prevalence of adenocarcinoma in our series.

Conclusions Significant differences in clinical characteristics and outcomes have been demonstrated between patients with PET positive and PET negative solitary pulmonary nodules. The overall prevalence of malignancy in patients with PET negative nodules $(15 / 41[36.6 \%])$ was higher than that reported in previous studies.

Abstract P162 Table 1 Comparison of clinical characteristics and outcomes of patients with PET positive and PET negative solitary pulmonary nodules

\begin{tabular}{|c|c|c|c|}
\hline & $\begin{array}{l}\text { PET positive } \\
(n=103)\end{array}$ & $\begin{array}{l}\text { PET negative } \\
(n=41)\end{array}$ & p Value \\
\hline \multicolumn{4}{|l|}{ Clinical and radiologic } \\
\hline Age & $70.4(9.2)$ & $69.2(10.0)$ & 0.506 \\
\hline Male gender & $47(45.6 \%)$ & $21(51.2 \%)$ & 0.367 \\
\hline Smoking history (Current or former) & $81(78.6 \%)$ & $29(70.7 \%)$ & 0.368 \\
\hline Diabetes & $7(6.8 \%)$ & $4(9.8 \%)$ & 0.546 \\
\hline Outline of nodule & & & 0.008 \\
\hline Spiculated & $65(63.1 \%)$ & $17(41.5 \%)$ & \\
\hline Lobulated & $28(27.2 \%)$ & $13(31.7 \%)$ & \\
\hline Smooth & $6(5.8 \%)$ & $10(24.4 \%)$ & \\
\hline Other & $4(3.9 \%)$ & $1(2.4 \%)$ & \\
\hline Morphology of nodule & & & 0.794 \\
\hline Solid & $89(86.4 \%)$ & $33(80.5 \%)$ & \\
\hline Subsolid & $14(13.6 \%)$ & $8(19.5 \%)$ & \\
\hline Pure ground glass & - & - & \\
\hline Median (range) nodule size (mm) & $17.0(9-28)$ & $13.0(8-23)$ & $<0.001$ \\
\hline Growth on serial CTs/CT and PET & & & $<0.001$ \\
\hline Yes & $27(26.2 \%)$ & $12(29.3 \%)$ & \\
\hline No & $19(18.4 \%)$ & $24(58.5 \%)$ & \\
\hline Data not available & $57(55.3 \%)$ & $5(12.2 \%)$ & \\
\hline \multicolumn{4}{|l|}{ Outcomes } \\
\hline MDT decision & & & $<0.001$ \\
\hline Histology & $81(78.6 \%)$ & $8(19.5 \%)$ & \\
\hline CT follow-up & $4(3.9 \%)$ & $29(70.7 \%)$ & \\
\hline Other & $18(17.5 \%)$ & $4(9.8 \%)$ & \\
\hline Treatment & & & $<0.001$ \\
\hline Surgical resection & $58(56.3 \%)$ & $12(29.3 \%)$ & \\
\hline Radical RT & $23(22.3 \%)$ & $3(7.3 \%)$ & \\
\hline Other & $22(21.4 \%)$ & $26(63.4 \%)$ & \\
\hline $\begin{array}{l}\text { Median (range) time to } \\
\text { diagnosis (days) }\end{array}$ & $45(15-721)$ & $145(6-801)$ & $<0.001$ \\
\hline 2 year mortality & $22(21.4)$ & $6(14.6)$ & 0.357 \\
\hline Final diagnosis & & & $<0.001$ \\
\hline Lung cancer & $82(79.6 \%)$ & $11(26.8 \%)$ & \\
\hline Adenocarcinoma & 61 & 12 & \\
\hline Non-adenocarcinoma & 21 & 1 & \\
\hline Other cancer & $9(8.7 \%)$ & $4(9.8 \%)$ & \\
\hline Benign & $10(9.7 \%)$ & $22(53.7 \%)$ & \\
\hline Indeterminate & $2(1.9 \%)$ & $4(9.8 \%)$ & \\
\hline
\end{tabular}

\section{P163 FACTORS INFLUENCING HISTOLOGICAL CONFIRMATION OF DIAGNOSIS IN LUNG CANCER PATIENTS}

doi:10.1136/thoraxinl-2011-201054c.163

S Chandramouli, M Cheema. Wirral University Teaching Hospital NHS Foundation Trust, Liverpool, UK

Background The National Lung Cancer Audit routinely reports to each unit the percentage of their patients who have received histological confirmation of a diagnosis of lung cancer. This could therefore be interpreted as a key performance indicator for a cancer unit. We studied the factors that influenced the rate of histological confirmation of diagnosis in our population.

Methods Data were extracted from our existing lung cancer database from January 2009 to May 2011. Demographics and clinical data were analysed to assess the factors that led to failure of confirmation of histological diagnosis. 
Results Out of 907 patients with lung cancer, 183 (20\%) did not have a histological diagnosis. Based on TNM staging, 10\% had stage I, $5 \%$ stage II, 19\% stage III and 50\% stage IV disease. Co-morbidities were significant in this group $-57 \%$ had severe COPD, $12 \%$ had IHD and $11 \%$ had had a previous CVA. Of the 183 patients identified, $49(27 \%)$ had at least one attempt at obtaining histology that proved to be non-diagnostic, either bronchoscopy (46 pts) or other procedure (3 pts). 41 (22\%) were actively treated-6 (15\%) had radical treatment, 5 (12\%) had palliative chemotherapy and 29 (70\%) had palliative radiotherapy. Performance status (PS) and comorbidities were the main factors affecting decision to obtain histology. As the Abstract P163 table 1 suggests, patients without histology tended to be older $(p<0.0008)$ and a greater proportion had a PS of three or more.

\section{Abstract P163 Table 1}

\begin{tabular}{lll}
\hline Characteristic & Histology $(\mathbf{N}=\mathbf{7 2 4})$ & No histology $(\mathbf{N}=\mathbf{1 8 3})$ \\
\hline Mean age (SD) & $72(11)$ & $75(10)$ \\
Men & $52 \%$ & $53 \%$ \\
1 yr mortality & $60 \%$ & $75 \%$ \\
PS of 3 or more & $210(29 \%)$ & $115(63 \%)$ \\
Stage 3-4 & $484(67 \%)$ & $126(69 \%)$ \\
\hline
\end{tabular}

Conclusion These data suggest that patients who do not ultimately receive histological confirmation of a diagnosis of lung cancer are a heterogenous population. In most cases the factors that influenced the failure to obtain histology were poor performance status and comorbidities. We conclude that the percentage of lung patients without histological confirmation of diagnosis may ultimately reflect the overall health of the local population rather than the specific quality of a lung cancer unit's clinical practice. As such we would advocate caution when interpreting differences in this parameter between units.

\section{P164 EGFR MUTATION PREVALENCE IN PATIENTS WITH NON- SMALL CELL LUNG CANCER: AN AUDIT OF TESTING WITHIN THE NORTH OF ENGLAND CANCER NETWORK}

doi:10.1136/thoraxjnl-2011-201054c.164

${ }^{1} \mathrm{~N}$ E Chamberlin, ${ }^{2} \mathrm{~A}$ C Ward. ${ }^{1}$ Freeman Hospital Respiratory Department, Newcastle upon Tyne, UK; ${ }^{2}$ North of England Cancer Network Lung NSSG, Newcastle upon Tyne, UK

In July 2010, NICE published a technology appraisal relating to the use of a Tyrosine Kinase Inhibitor (TKI) as first line treatment for patients with locally advanced or metastatic non-small cell lung cancer (NSCLC) in whom an epidermal growth factor receptor (EGFR) mutation was found. Subsequently, the North of England Cancer Network implemented region wide testing for EGFR mutations in all patients with a pathological confirmation of NSCLC. A retrospective audit was undertaken to assess the quality of EGFR mutation testing, and to obtain data regarding those patients who had tested positive in order to improve local policy.

Methods Lung cancer MDT lead clinicians from every NHS trust in the region were contacted and asked to provide information about every patient with a confirmed diagnosis of NSCLC for whom specimens had been sent for EFGR mutation testing between October 2010 and February 2011.

Results The 9 trusts identified 314 patients in whom specimens had been sent for EGFR mutation testing; 161 (51\%) males; average age 69 years (34-91); 60\% were WHO performance status $0-1 ; 95 \%$ were current or ex-smokers; 47\% (149) had stage 4 disease. 60 (19\%) were female with adenocarcinoma. In $22(7 \%)$ patients an EGFR mutation was found, 16 (73\%) were female, 17 (77\%) were current or ex smokers, $73 \%$ had stage 4 disease. 13 were female with adenocarcinoma, therefore prevalence in this group was 22\% (cf $7 \%$ for whole local population). 14 (64\% of EGFR mutation positive patients, and $4 \%$ of all patients tested) were treated with a TKI as first line, (23\% had best supportive care, 13\% surgery). EGFR mutation testing failed in $29(9 \%)$ patients. The total cost of testing for this period is over $£ 47000$.

Conclusions Local prevalence of EGFR mutations in all patients with NSCLC is $7 \%$, but $22 \%$ for female patients with a diagnosis of adenocarcinoma. Prior to this audit, specimens were sent for testing by the pathologist on confirmation of a diagnosis of NSCLC. Local policy has changed as a result of this audit. Specimens are now sent for testing after discussion at the MDM, at the point of referral to Oncology.

Abstract P164 Table 1 EGFR mutation positive patients

\begin{tabular}{|c|c|c|c|c|c|c|c|c|}
\hline & Sex & Age & PS & Cell type & $\begin{array}{l}\text { Histology/ } \\
\text { cytology }\end{array}$ & Stage & 1 therapy & $\begin{array}{l}\text { Smoking } \\
\text { status }\end{array}$ \\
\hline 1 & Female & 32 & 0 & Adeno & Histology & T4N2M1b & TKI & Never \\
\hline 2 & Female & 57 & 0 & Adeno & Histology & T3N0M1b & TKI & Current \\
\hline 3 & Female & 48 & 0 & Adeno & Histology & T1aN3M1a & TKI & Current \\
\hline 4 & Female & 63 & 0 & Adeno & Cytology & T3N2M0 & TKI & Ex \\
\hline 5 & Female & 65 & 0 & Adeno & Histology & T4N2M1b & TKI & Current \\
\hline 6 & Female & 62 & 1 & Adeno & Histology & T3N3M1b & TKI & Ex \\
\hline 7 & Female & 66 & 1 & Adeno & Histology & T2NOMO & Surgery & Current \\
\hline 8 & Female & 84 & 1 & Adeno & Histology & T3NOMO & TKI & Never \\
\hline 9 & Female & 56 & 1 & Adeno & Cytology & T2bN2M1a & TKI & Ex \\
\hline 10 & Female & 73 & 2 & Adeno & Cytology & T2aNxM1b & TKI & Never \\
\hline 11 & Female & 64 & 2 & Adeno & Histology & T2aN2M1b & TKI & Ex \\
\hline 12 & Female & 62 & 3 & Adeno & Histology & T1N0M1b & $\begin{array}{l}\text { Best } \\
\text { supportive }\end{array}$ & Ex \\
\hline 13 & Female & 69 & 3 & Adeno & Cytology & T3N3Mx & $\begin{array}{l}\text { Best } \\
\text { supportive }\end{array}$ & Ex \\
\hline 14 & Female & 40 & 1 & Large cell & Cytology & T2aN2M1a & Surgery & Never \\
\hline 15 & Female & 62 & 1 & Large cell & Cytology & T4N2M1a & $\begin{array}{l}\text { Best } \\
\text { supportive }\end{array}$ & Ex \\
\hline 16 & Female & 69 & 2 & Large cell & Cytology & T2aNOM1a & $\begin{array}{l}\text { Best } \\
\text { supportive }\end{array}$ & Current \\
\hline 17 & Male & 55 & 0 & Adeno & Histology & T2N3M1a & TKI & Current \\
\hline 18 & Male & 91 & 0 & Adeno & Cytology & T2NOMO & $\begin{array}{l}\text { Best } \\
\text { supportive }\end{array}$ & Ex \\
\hline 19 & Male & 71 & 1 & Adeno & Cytology & T4N2M1b & TKI & Never \\
\hline 20 & Male & 69 & 3 & Adeno & Histology & T1bN2M1b & TKI & Ex \\
\hline 21 & Male & 77 & 1 & Squamous & Histology & T4N3M1b & TKI & Ex \\
\hline 22 & Male & 57 & 1 & Squamous & Histology & T2bNOMO & Surgery & Ex \\
\hline
\end{tabular}

\section{Infections: from vaccination to treatments} P165 NON-TUBERCULOSIS MYCOBACTERIUM INFECTION IN
CYSTIC FIBROSIS LUNG DISEASE; EFFECTS ON BACTERIAL
COMMUNITY

doi:10.1136/thoraxinl-2011-201054c.165

R Sattar. University of Southampton, Southampton, UK

Background Species of Non-Tuberculosis Mycobacterium (NTM), mainly Mycobacterium abscessus ( $M$ abscessus) is of increasing concern in Cystic Fibrosis (CF). $M$ abscessus are present in the CF lungs as part of the complex microbiological community. The mode of growth of $M$ abscessus in vitro is in biofilms; this maybe a contributing factor for the resistance to antimicrobial agents. Lung infections with $M$ abscessus is a major concern in CF patients, as it is difficult to treat them. It has been described that, fatal infections are likely to occur after lung transplantations; therefore pre-transplant colonisation with $M$ abscessus has become a relative contraindication to lung transplantation. NTM are recognised pathogens in the CF airways, but associations with clinical outcomes still remains unclear. 
However, a potential important confounding factor may explain a part of their results: undiagnosed pulmonary embolism (PE), mimicking (or induced by) COPD exacerbation. Troponin and BNP are factors associated with poor prognosis in $\mathrm{PE}^{2}$ COPD is associated with an increased risk of deep venous thrombosis and PE (particularly during exacerbation) and with an increased risk of fatal $\mathrm{PE}^{3}$ In particular, COPD is associated with increased risk of death from undiagnosed PE. ${ }^{4}$

The real incidence of PE during exacerbation of COPD is not clearly known, ranging from $1.5 \%$ to $24.7 \%{ }^{5}$ corresponding to the incidence of elevated troponin and BNP, as noted by Chang et al in their cohort. Therefore, it would be of great interest if Chang et al could provide us some precise answers:

- In how many of the 250 patients a PE has been evoked and/or eliminated?

- How many patients were under efficient anticoagulant drugs at inclusion?

- How many patients received thromboprophylaxis, as a significant number of patients included presented other PE risk factors such as malignancy or cerebrovascular diseases?

Because of reserved prognosis of COPD patients with $\mathrm{PE}$, and of the availability of preventive and curative specific drugs, COPD patients admitted with exacerbation and with abnormal cardiac biomarkers may require a $\mathrm{PE}$ screening and effective thromboprophylaxis if PE has been ruled out.

\section{Laurent Bertoletti, ${ }^{1,2,3}$ Patrick Mismetti, ${ }^{1,2,3}$ Hervé Decousus ${ }^{1,2,3}$}

${ }^{1}$ Université Jean-Monnet, Thrombosis Research Group, St-Etienne, France; ${ }^{2}$ INSERM, CIC-CIE3, St-Etienne, France; ${ }^{3}$ Centre Hospitalier Universitaire, Service de Médecine Interne et Thérapeutique, St-Etienne, France

Correspondence to Dr Laurent Bertoletti, Centre Hospitalier Universitaire, Service de Médecine Interne et Thérapeutique, CHU de St-Etienne, Saint-Etienne 42023, France; laurent.bertoletti@gmail.com

\section{Competing interests None.}

Contributors $\mathrm{LB}, \mathrm{PM}$ and $\mathrm{HD}$ analysed the data and drafted the manuscript.

Provenance and peer review Not commissioned; internally peer reviewed.

Accepted 26 May 2011

Published Online First 18 June 2011

Thorax 2012;67:177-178.

doi:10.1136/thoraxjnl-2011-200416

\section{REFERENCES}

1. Chang CL, Robinson SC, Mills GD, et al. Biochemical markers of cardiac dysfunction predict mortality in acute exacerbations of COPD. Thorax 2011;66:764-8.

2. Lega JC, Lacasse $Y$, Lakhal $L$, et al. Natriuretic peptides and troponins in pulmonary embolism: a meta-analysis. Thorax 2009;64:869-75.
3. Laporte S, Mismetti $P$, Décousus $\mathrm{H}$, et al. Clinical predictors for fatal pulmonary embolism in 15,520 patients with venous thromboembolism: findings from the Registro Informatizado de la Enfermedad TromboEmbolica venosa (RIETE) Registry. Circulation 2008;117:1711-16.

4. Pineda LA, Hathwar VS, Grant BJ. Clinical suspicion of fatal pulmonary embolism. Chest 2001;120:791-5

5. Rizkallah J, Man SF, Sin DD. Prevalence of pulmonary embolism in acute exacerbations of COPD: a systematic review and meta-analysis. Chest 2009;135:786-93.

\section{Authors' response}

We thank Bertoletti and colleagues for raising the important issue of pulmonary embolism (PE) in the exacerbation of chronic obstructive pulmonary disease (COPD). ${ }^{1}$ Although we did not routinely investigate for $\mathrm{PE}$ in our cohort, we excluded any patients with suspected or confirmed PE from the study. ${ }^{2}$ Unfortunately, it is difficult to detect thromboembolic events in this population and it is possible that we included some patients with subclinical pulmonary emboli. It is also plausible that this contributed to the association between elevated cardiac biomarkers and mortality. However, we think that this is unlikely to be the only mechanism.

Thromboprophylaxis was administered to some patients during their admission depending on their immobility and other risk factors, but this would not have influenced the NT-proBNP or troponin T results obtained on presentation. We did not collect information on pre-existing anticoagulation therapy on admission to the study.

Further research into the mechanism linking elevated cardiac biomarkers and mortality in COPD exacerbation is needed. We agree with Bertoletti and colleagues that investigating the contribution of concurrent $\mathrm{PE}$ is important, as this is something that can be treated.

\section{L Chang, ${ }^{1}$ R J Hancox ${ }^{1,2}$}

${ }^{1}$ Department of Respiratory Medicine, Waikato Hospital, Hamilton, New Zealand: ${ }^{2}$ Department of Preventive and Social Medicine, University of Otago, Dunedin, New Zealand

Correspondence to $\mathrm{Dr} C \mathrm{~L}$ Chang, Department of Respiratory Medicine, Waikato Hospital, Level 01 Menzies Building, Waikato Hospital, Hamilton 3204 New Zealand; contact_cat@hotmail.com

\section{Competing interests None.}

Provenance and peer review Not commissioned; internally peer reviewed.

Accepted 25 May 2011

Published Online First 18 June 2011

Thorax 2012;67:178.

doi:10.1136/thoraxinl-2011-200512

\section{REFERENCES}

1. Bertoletti L, Mismetti P, Decousus H. The cloud of pulmonary embolism during COPD exacerbation. Thorax 2012;67:178

2. Chang CL, Robinson SC, Mills GD, et al. Biochemical markers of cardiac dysfunction predict mortality in acute exacerbations of COPD. Thorax 2011;66:764-8.

\section{CORRECTIONS}

doi:10.1136/thoraxjnl-2011-201054c.151corr1

Thorax 2011;66:A128-A129 doi:10.1136/ thoraxinl-2011-201054c.151. P151 Cost of pulmonary rehabilitation is offset by reduction in healthcare utilisation. The author list and author affiliations for this poster should read: ${ }^{1} \mathrm{~S}$ Kibe, ${ }^{1} \mathrm{D}$ Ford, ${ }^{2}$ S Hart. 1 Scarborough General Hospital, Scarborough, UK; 2 Castle Hill Hospital, Hull, UK.

doi:10.1136/thoraxjnl-2011-201054c.163corr1

Thorax 2011;66:A133-A134 doi:10.1136/ thoraxjnl-2011-201054c.163. P163 Factors influencing histological confirmation of diagnosis in lung cancer patients. The author list for this poster should read: S Chandramouli, M Cheema, J Corless. Wirral Lung Unit, Arrowe Park Hospital, Wirral CH49 5PE, UK.

doi:10.1136/thoraxjnl-2011-201054c.233corr1

Thorax 2011;66:A162-A163 doi:10.1136/ thoraxinl-2011-201054c.233. P233 Judicious use of oximetry can help deliver cost effective sleep service. The author list and affiliation for this poster should read: C L Collins, B Balakrishnan, J Madieros, M Sovani. Queen's Medical Centre, Nottingham University Hospitals, Nottingham, UK.

doi:10.1136/thoraxjnl-2011-201054c.179corr1

Thorax 2011;66:A140 doi:10.1136/ thoraxjnl-2011-201054c.179. P179 The changing numbers and indications of mediastinoscopy procedures performed following the introduction of endobronchical ultrasound at a UK tertiary centre. The author list and affiliations for this poster should read: ${ }^{1} \mathrm{M}$ Bakir, ${ }^{2} \mathrm{R}$ Breen, ${ }^{2} \mathrm{~A}$ Quinn, ${ }^{2} \mathrm{~J}$ King, ${ }^{1} G$ Santis. 1 Kings College London, London, UK; 2 Guy's and St Thomas' NHS Foundation Trust, London, UK. 